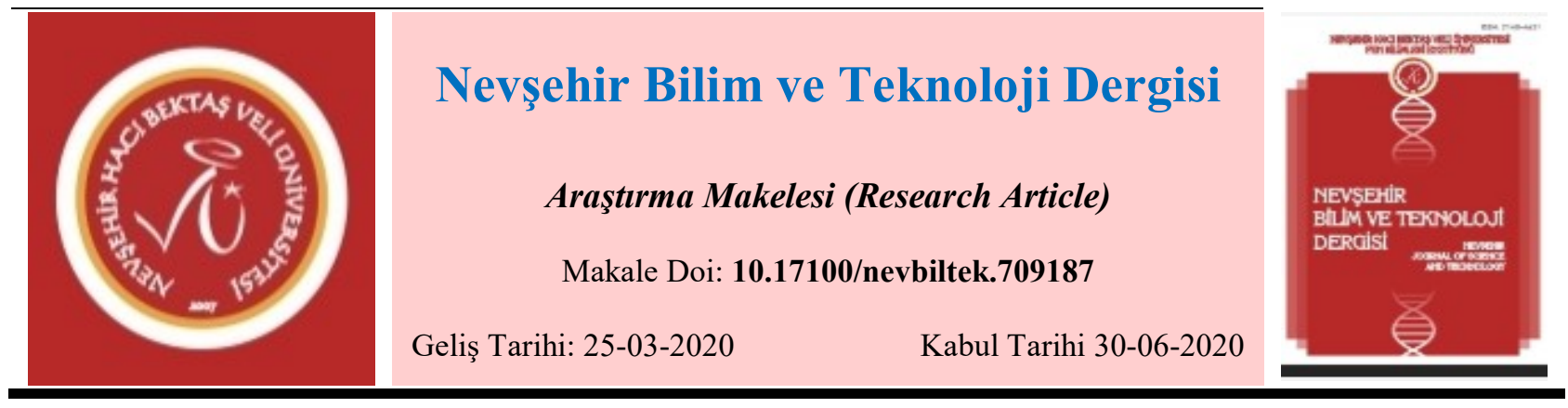

\title{
Demir-Çelik Üretim Tesisi Fan Tozu Atığının Seramik Sırda Kullanılabilirliğinin İncelenmesi
}

\author{
Zahide Bayer ÖZTÜRK ${ }^{1,}$, Ahmet SARI ${ }^{2}$ \\ ${ }^{1}$ Nevşehir Üniversitesi, Mühendislik ve Mimarlık Fakültesi, Metalurji ve Malzeme Mühendisliği Bölümü, Nevşehir \\ ORCID ID: \\ ${ }^{2}$ Nevşehir Üniversitesi, Mühendislik ve Mimarlık Fakültesi, Metalurji ve Malzeme Mühendisliği Bölümü, Nevşehir \\ ORCID ID:
}

\section{Özet}

Tüm endüstriyel alanlarda pigmentler ve boyalar renklendirici olarak kullanılırlar. Pigment ve boyalar seramik bünyeler, engoplar ve sırlar için önemli bir değere sahiptir. Dünyadaki gelişmelere paralel olarak, inşaat ve seramik endüstrilerinin hızlı gelişimi ile birlikte, doğal kaynakların kullanılabilirliği her dönemde önemini koruyacaktır. Son on yılda sürdürülebilir üretim için temel taleplerden biri endüstriyel atıkların geri dönüşümüdür. Bu çalışmada Mersin Çimsatas firmasından temin edilen fan tozunun fritle hazırlanan seramik sırlarına farklı oranlarda ilave edilmesi ile sırlarda renklendirici olarak değerlendirilebilirliği incelenmiștir. Fan tozu ham ve $1000-1100{ }^{\circ} \mathrm{C}^{\prime} \mathrm{de}$ kalsine edilerek sırlara eklenmiş ve farklı sıcaklıklarda sinterlenmiştir. Sinterleme sonrası numunelerin L-a*-b* renk parametreleri incelenmiştir. Herhangi bir çatlak oluşturmadan sırlarda kahve tonlarının elde edildiği ve fan tozunun renklendirici bir hammadde olarak değerlenebileceği belirlenmiştir.

Anahtar kelimeler: Sır, fan tozu atı̆̆ı, renk paramereleri.

\section{Investıgation Of The Usabılity Of Fan Powder Waste In Iron And Steel Production Plant For Ceramic Glaze}

\begin{abstract}
Pigments and dyes are used as colorants in all industrial areas. They have an important value for ceramic bodies, engobes and glazes. In parallel with the developments in the world, with the rapid development of the construction and ceramic industries, the availability of natural resources will remain important in every period. One of the main demands for sustainable production in the last decade is the recycling of industrial wastes. In this study, it has been investigated that the fan powder obtained from Mersin Çimsataş Company is added to ceramic glazes prepared with frit in different proportions and evaluated as colorant in glazes. The fan powder is calcined at $1000-1100^{\circ} \mathrm{C}$, and added to glazes as raw, calcined forms then sintered at different firing temperatures. After sintering, L-a*-b* color parameters of the samples were examined. It was determined that brown tones were obtained in the glaze without creating any crack and fan powder could be used as a coloring raw material for ceramic glazes
\end{abstract}

Keywords: Glaze, fan powder waste, color parameters.

“Bu makale, 4. International Conference on Material Science and Technology in Klzulcahamam/ANKARA(IMSTEC 2019) kongresinde sözlü sunum yapulmıștır",

1. Giriş 
Son yıllarda endüstriyel gelişmelerin hızlanması ile sanayi alanlarında üretim faaliyetleri artmıştır. Artan üretim faaliyetleri hammadde ihtiyacını da beraberinde getirmektedir. Doğal hammadde kaynaklarının sınırlı olması, nakliye sorunu gibi bazı nedenler alternatif hammadde kaynağı arayışına yönlendirmektedir. Bu noktada gündeme gelen konulardan biri de endüstriyel üretim atıklarının değerlendirilmesine yönelik çalışmalardır. Üretim sonrası ortaya çıkan atıkların seramik sırlarında [1-6], seramik bünyelerinde [7-8], camlarda [9-10], cam-seramiklerde [9,11], bims üretiminde [12] kullanımını araştıran çalışmalar literatürde mevcuttur.

Seramik bünye, sır, astar renklendirmelerinde birçok renk verici bileşen tek başına veya diğer renk verici malzemeler ile birlikte kullanılmaktadır [3]. Doğal pigmentler doğada basit oksitler olarak bulunmaktadır [2]. Bazı atıkların yüksek oranda $\mathrm{SiO}_{2}, \mathrm{Al}_{2} \mathrm{O}_{3}, \mathrm{Fe}_{2} \mathrm{O}_{3}, \mathrm{CaO}, \mathrm{MgO}, \mathrm{K}_{2} \mathrm{O}, \mathrm{ZnO}$ vb. içeriyor olması seramik sır ve bünyelerinde kullanılabilme potansiyelini ortaya koymaktadır [13]. Sır bileşiminde atık oranı değiştirilerek mükemmel renk çeşitliliği ve doku elde edilebilir [14].

Demir ve çelik cevherinin zenginleştirmesinde ve üretiminde konsantre atıklar ortaya çıkmaktadır. Bu çalışmada Mersin'de bulunan, Çukurova İnşaat Makinaları San. Ve Tic. A.Ş.'den temin edilen, demir ve çelik cevherinin üretimi sırasında oluşan fan tozu atıklarının renkli sır üretimi için kullanılabilirliği araştırılmış̧ır. Sır bileşimlerine \%5-15 oranında ilave edilen ham ve kalsine edilen fan tozlarının seramik yüzeylerde $1000^{\circ} \mathrm{C}$ ve $1100^{\circ} \mathrm{C}$ 'de sinterlenmesi sonucu oluşan renk etkileri araştııılmıştır. Sırlı karoların renk parametrelerini $(\mathrm{L}, \mathrm{a} *, \mathrm{~b} *)$ karşılaştırmak için spektrometre kullanılmıştır. Bu atığın seramik sır sektöründe renklendirici olarak kullanılabilmesi, renkli sır üretimine ve ülke ekonomisine katkı sağlayacaktır.

\section{Materyal ve Metot}

Öncelikle kullanılacak olan konsantre demir ve çelik cevheri atıkları (fan tozu), 3-4 saat boyunca $1000^{\circ} \mathrm{C}$ ve $1100^{\circ} \mathrm{C}^{\prime} \mathrm{de}$ Carbolite marka laboratuvar tipi firında kalsine edilmiştir. Fan tozunun Ekmekçioğulları Metal ve Kimya SAN. TíC. A.Ş.'de ICP-OES ile gerçekleştirilen kimyasal analiz ve elek analiz sonuçları Tablo 1-2'de sunulmuştur. Gizem Frit (Sakarya) firmasından temin edilen transparant ve opak frit bileşimlerine kalsine edilen atıktan ağırlıkça \% 5-15 oranında eklenmiştir. Gizem frit firmasından temin edilen fritlerin kimyasal analiz sonuçları Tablo 3'dedir. \%92 firit, $\% 8$ oranında kaolen ve ham-kalsine edilen fan tozu ilaveli sır bileşimleri engoplu karolar üzerine daldırma yöntemi ile uygulanarak sırlı karolar $1000^{\circ} \mathrm{C}$ ve $1100^{\circ} \mathrm{C}$ 'de laboratuvar tipi firında sinterlenmiştir. Renk parametreleri spektrometre ile ölçülmüştür.

Tablo 1. Fan tozunun kimyasal analiz sonuçları

\begin{tabular}{|c|c|}
\hline Element & \% Miktar \\
\hline Alüminyum (Al) & 0,112 \\
\hline Arsenik (As) & $<0,0003$ \\
\hline Altın (Au) & $<0,0002$ \\
\hline Antimon (Sb) & $<0,0002$ \\
\hline Bakır (Cu) & 0,019 \\
\hline Bor (B) & 0,020 \\
\hline Baryum (Ba) & 0,001 \\
\hline Berilyum (Be) & 0,0003 \\
\hline Bizmut (Mi) & $<0,0003$ \\
\hline Civa (Hg) & $<0,003$ \\
\hline Çinko (Zn) & 0,008 \\
\hline Demir (Fe) & 7,58 \\
\hline Fosfor (P) & 0,003 \\
\hline
\end{tabular}


Nevşehir Bilim ve Teknoloji Dergisi (2019), 9 (IMSTEC Özel Sayı),111-117

\begin{tabular}{|c|c|}
\hline Germanyum $(\mathrm{Ge})$ & $<0,001$ \\
\hline Kalsiyum $(\mathrm{Ca})$ & 0,017 \\
\hline Kadminyum $(\mathrm{Cd})$ & 0,0002 \\
\hline Kobalt $(\mathrm{Co})$ & 0,001 \\
\hline Krom $(\mathrm{Cr})$ & 0,023 \\
\hline Kalay $(\mathrm{Sn})$ & $<0,001$ \\
\hline Kükürt $(\mathrm{S})$ & 0,045 \\
\hline Kurşun $(\mathrm{Pb})$ & $<0,0002$ \\
\hline İndiyum $(\mathrm{In})$ & 0,002 \\
\hline Potasyum $(\mathrm{K})$ & 0,036 \\
\hline Magnezyum $(\mathrm{Mg})$ & 0,038 \\
\hline Mangan $(\mathrm{Mn})$ & 0,106 \\
\hline Molibden $(\mathrm{Mo})$ & 0,007 \\
\hline Nikel $(\mathrm{Ni})$ & 0,005 \\
\hline Sodyum $(\mathrm{Na})$ & 0,253 \\
\hline Selenyum $(\mathrm{Se})$ & $<0,001$ \\
\hline Silisyum $(\mathrm{Si})$ & 0,416 \\
\hline Stronsiyum & $<0,0001$ \\
\hline Titanyum (Ti) & 0,010 \\
\hline Vanadyum (V) & 0,001 \\
\hline
\end{tabular}

Tablo 2. Fan tozunun elek analizi sonuçları

\begin{tabular}{|l|l|}
\hline Elek analiz aralikları & $\%$ Miktar \\
\hline$+1 \mathrm{~mm}$ & 5,34 \\
\hline$+500 \mu \mathrm{m}$ & 5,30 \\
\hline$+212 \mu \mathrm{m}$ & 29,48 \\
\hline$+125 \mu \mathrm{m}$ & 45,48 \\
\hline$+75 \mu \mathrm{m}$ & 11,43 \\
\hline$-75 \mu \mathrm{m}$ & 2,97 \\
\hline
\end{tabular}

Tablo 3. Kullanılan fritlerin oksit bileşimi

\begin{tabular}{|l|l|l|}
\hline Oksitler & Opak frit & Transparant frit \\
\hline $\mathrm{K}_{2} \mathrm{O}+\mathrm{Na}_{2} \mathrm{O}$ & $17,5-18$ & $4,5-5,5$ \\
\hline $\mathrm{CaO}+\mathrm{MgO}$ & $3,5-4$ & $7-7,5$ \\
\hline $\mathrm{Al}_{2} \mathrm{O}_{3}$ & $14-15$ & $10-11$ \\
\hline $\mathrm{B}_{2} \mathrm{O}_{3}$ & $5-6$ & $19-21$ \\
\hline $\mathrm{SiO}_{2}$ & $49-51$ & $56-58$ \\
\hline $\mathrm{ZrO}_{2}$ & $8-9$ & - \\
\hline $\mathrm{Fe}_{2} \mathrm{O}_{3}+\mathrm{TiO}_{2}$ & $\leq 0,1$ & $\leq 0,1$ \\
\hline
\end{tabular}

\section{Bulgular}

Hazırlanan sır bileşimleri Tablo 4'de verilmiştir. Sırlama ve pişirme sonrası elde edilen sırlı yüzey görüntüleri Şekil 14'de sunulmuştur. Minolta C-300 renk ölçüm cihazı ile ölçülen L-a*-b* koordinatları ise Tablo 5-6'da sunulmuştur.

Tablo 4. Hazırlanan bileşimlerin kodlamaları

\begin{tabular}{|l|l|l|l|l|}
\hline Değişkenler & \multicolumn{4}{|c|}{ Seviyeleri } \\
\hline Frit Türü & Opak (O) & $\begin{array}{l}\text { Transparant } \\
(\mathrm{T})\end{array}$ & - & - \\
\hline $\begin{array}{l}\text { Atık } \\
\text { kalsinasyon } \\
\text { sicaklığ } 1\left({ }^{\circ} \mathrm{C}\right)\end{array}$ & 0 & 1000 & 1100 & - \\
\hline $\begin{array}{l}\text { Atık katk1 } \\
\text { miktarı }(\%)\end{array}$ & 0 & 5 & 10 & 15 \\
\hline $\begin{array}{l}\text { Sinterleme } \\
\text { sicaklığ } 1\left({ }^{\circ} \mathrm{C}\right)\end{array}$ & 1000 & 1100 & - & - \\
\hline
\end{tabular}


Nevşehir Bilim ve Teknoloji Dergisi (2019), 9 (IMSTEC Özel Sayı),111-117

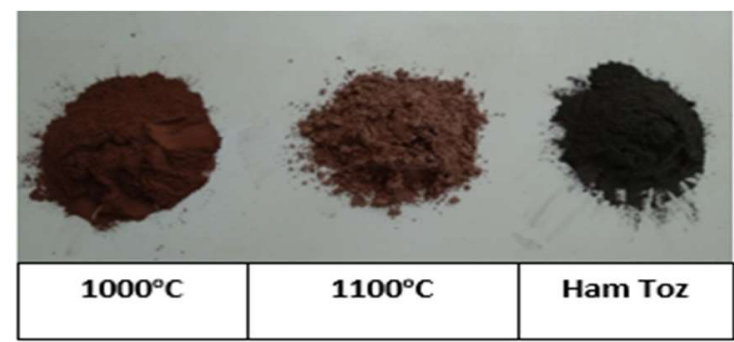

Şekil 1. Ham halde bulunan, 1000 ve $1100^{\circ} \mathrm{C}$ 'de kalsine edilmiş olan fan tozunun görüntüleri

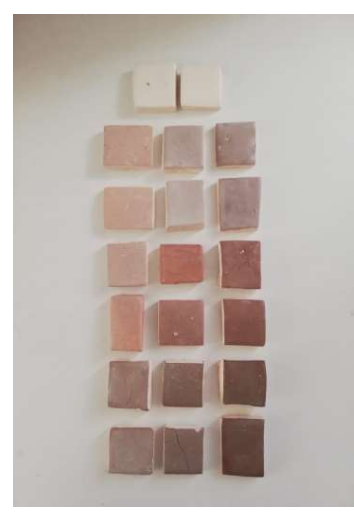

Şekil 2. $1000^{\circ} \mathrm{C}$ 'de sinterlenen opak sırlı numunelerin görüntüleri

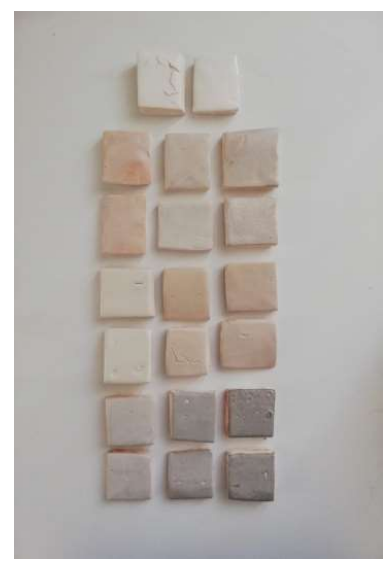

Şekil 3. $1100^{\circ} \mathrm{C}$ 'de sinterlenen opak sırlı numunelerin görüntüleri 


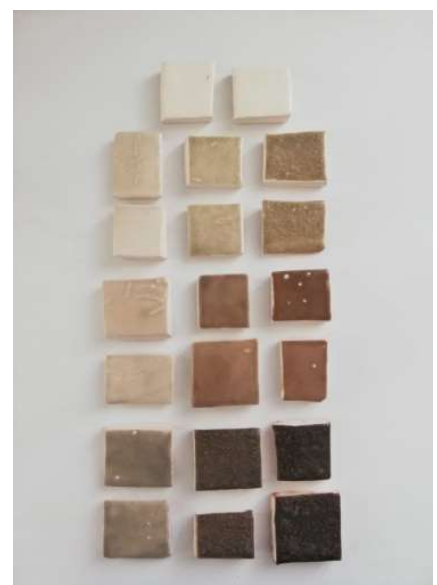

Şekil 4. $1000^{\circ} \mathrm{C}$ 'de sinterlenen transparant sırlı numunelerin görüntüleri

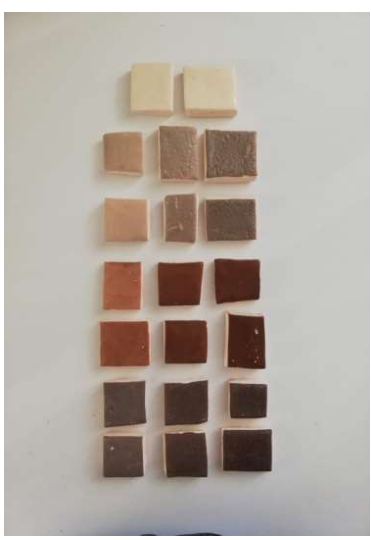

Şekil 5. $1100^{\circ} \mathrm{C}$ 'de sinterlenen transparant sırlı numunelerin görüntüleri

Tablo 5. Opak sırlı numunelerin sinterleme sonrası renk ölçüm değerleri

\begin{tabular}{|c|c|c|c|c|c|c|}
\hline \multirow[t]{2}{*}{ Numuneler } & \multicolumn{3}{|c|}{$\begin{array}{l}1000^{\circ} \mathrm{C} \text { 'de sinterlenen } \\
\text { numuneler }\end{array}$} & \multicolumn{3}{|c|}{$\begin{array}{l}1100^{\circ} \mathrm{C} \text { 'de sinterlenen } \\
\text { numuneler }\end{array}$} \\
\hline & $\bar{L}$ & $\mathrm{a}^{*}$ & $\mathrm{~b}^{*}$ & $\mathrm{~L}$ & $a^{*}$ & $\mathrm{~b}^{*}$ \\
\hline std & 89,62 & 3,48 & 6,48 & 92,56 & 0,93 & 1,87 \\
\hline Ham- $\% 5$ & 72,87 & 8,71 & 8,93 & 82,03 & 4,51 & 7,80 \\
\hline Ham- $\% 10$ & 73,36 & 3,33 & 3,58 & 83,71 & 1,43 & 4,97 \\
\hline Ham- \%15 & 66,58 & 3,81 & 3,65 & 81,54 & 1,45 & 7,04 \\
\hline $1000^{\circ} \mathrm{C}-\% 5$ & 68,82 & 8,57 & 9,02 & 86,52 & 0,34 & 7,04 \\
\hline $1000^{\circ} \mathrm{C}-\% 10$ & 61,79 & 9,22 & 8,45 & 82,90 & 2,68 & 8,62 \\
\hline $1000^{\circ} \mathrm{C}-\% 15$ & 56,34 & 8,39 & 7,83 & 79,46 & 2,32 & 8,42 \\
\hline $1100^{\circ} \mathrm{C}-\% 5$ & 67,93 & 4,22 & 5,63 & 83,24 & 0,52 & 4,33 \\
\hline $1100^{\circ} \mathrm{C}-\% 10$ & 63,57 & 4,31 & 6,30 & 75,39 & 0,26 & 4,13 \\
\hline $1100^{\circ} \mathrm{C}-\% 15$ & 54,07 & 4,94 & 6,53 & 72,21 & 0,15 & 4,54 \\
\hline
\end{tabular}


Tablo 6. Transparant sırlı numunelerin sinterleme sonrası renk ölçüm değerleri

\begin{tabular}{|l|l|l|l|l|l|l|}
\hline \multirow{2}{*}{ Numuneler } & \multicolumn{3}{|l|}{$1000^{\circ} \mathrm{C}^{\prime}$ de sinterlenen } & \multicolumn{3}{l|}{$1100^{\circ} \mathrm{C}$ 'de sinterlenen } \\
numuneler & numueler & $\mathrm{b}^{*}$ \\
\cline { 2 - 7 } & $\mathrm{L}$ & $\mathrm{a}^{*}$ & $\mathrm{~b}^{*}$ & $\mathrm{~L}$ & $\mathrm{a}^{*}$ & $\mathrm{~b}^{*}$ \\
\hline std & 87,71 & 4,50 & 11,52 & 91,18 & 1,19 & 7,20 \\
\hline Ham-\%5 & 69,54 & 5,77 & 11,03 & 82,08 & 1,61 & 9,95 \\
\hline Ham-\%10 & 61,30 & 3,75 & 8,04 & 72,80 & 2,16 & 12,74 \\
\hline Ham- \%15 & 55,18 & 3,65 & 6,88 & 62,67 & 3,62 & 14,34 \\
\hline $1000^{\circ} \mathrm{C}-\% 5$ & 56,42 & 12,80 & 15,53 & 74,89 & 3,18 & 11,61 \\
\hline $1000^{\circ} \mathrm{C}-\% 10$ & 44,54 & 12,03 & 12,01 & 59,19 & 5,99 & 12,40 \\
\hline $1000^{\circ} \mathrm{C}-\% 15$ & 41,35 & 10,72 & 8,99 & 55,43 & 7,57 & 12,38 \\
\hline $1100^{\circ} \mathrm{C}-\% 5$ & 51,68 & 4,53 & 5,83 & 64,42 & 2,80 & 9,69 \\
\hline $1100^{\circ} \mathrm{C}-\% 10$ & 44,42 & 4,82 & 4,99 & 46,82 & 2,07 & 7,02 \\
\hline $1100^{\circ} \mathrm{C}-\% 15$ & 40,00 & 5,93 & 5,95 & 38,42 & 1,45 & 3,89 \\
\hline
\end{tabular}

\section{Tartışma ve Sonuç}

Atığın içerdiği demir nedeniyle standarda göre tüm numunelerin $L^{*}$ (açıklık) değerinde bir azalma görülmüştür. $L^{*}$ değerindeki en fazla düşüş standart sıra göre \%15 ilaveli sırlarda görülmüştür. Buna göre standart opak sırda L değeri 89,62 iken $1100^{\circ} \mathrm{C}$ 'de kalsine edilen $\% 15$ ilave atık içeren numunede bu değer 54,07 bulunmuştur. Transparant standart sırda L değeri 87,71 iken, $1100^{\circ} \mathrm{C}$ 'de kalsine edilen $\% 15$ ilave atık içeren numunede bu değer 40,00 olarak bulunmuştur. $a^{*}$ değeri kırmızılık derecesini ve $b^{*}$ değeri de sarılık derecesini göstermektedir. Bu değerlerin yüksek olduğu numunelerinde ilave katkı miktarının yüksek olduğu numunelerde elde edildiği görülmektedir. Çalısma sonucunda seramik karo sırlarında, sır frit bileşimine de bağlı olarak kahve ve gri renk tonlarının kullanıldığ dekorlamalarda renklendirici olarak, Çukurova İnşaat Makinaları San. Ve Tic. A.Ş. firması fan tozu atıklarının özellikleri bozmadan sırda renklendirici hammadde olarak kullanılabileceği tespit edilmiştir. Fan tozunun çok ince taneli olması ve farklı sıcaklıklarda 1sıl işleme tabi tutulduğunda $\left(1000-1100^{\circ} \mathrm{C}\right)$ kahve-gri tonlarını sağlaması önemli avantaj oluşturmuştur. Fan tozu atığının seramik sırlarda renklendirici olarak kullanılması durumunda hem temin edildiği firmanın atık depolama-tozlaşma sorununu ortadan kaldıracak, hem de seramik boya-renklendirici sektörüne katkı sağlayacaktır.

\section{Teşekkür}

Başta; atığın temin edilmesinde büyük emekleri olan Çukurova İnşaat Makinaları San. Ve Tic. A.Ş.'nin Planlama ve Stok Sorumlusu Hasan YALÇIN'a ve Çimsataş Çevre Sorumlusu, Çevre Mühendisi Ece GÜLER'e; çalışmada kullanılan frit ve desteği için Gizem Frit'e ve Seramik Ar-ge Müdürü Bünyamin ÖZTÜRK'e ve seramik altlıkların temininde yardımcı olan Güray Seramik firmasından Serkan DALKILIÇ’a sonsuz teşekkürler.

\section{Kaynaklar}

[1]. Çakı M.,"Baca tozlarının sırların renklendirilmesinde kullanılabilirliğinin araştırılması”, Uluslararası Seramik Kongresi bildiriler kitabı, Türk Seramik Derneği yayınları, 5, 241-249, 1991.

[2]. $\quad$ Eren Gultekin $\mathrm{E}$., " $\mathrm{Fe}_{2} \mathrm{O}_{3}$ içeren hammaddelerin şeffaf sırı renklendirme etkisi”, Dicle Üniversitesi Mühendislik dergisi, 8, 4, 865-870, 2017. 
[3]. Bayer Ozturk Z., Atay B., Çakı M., "Ferrokrom uçucu külünün duvar karosu sırındaki renk etkileri”, $A$ fyon Kocatepe Üniversitesi Fen Bilimleri dergisi, 89-94, özel say1, 2014.

[4]. Karasu B., Kaya G., "Potansiyel renklendirici olarak limonitin çeşitli seramik sırlarında değerlendirilmesi”, 4. Endüstriyel hammaddeler Sempozyumu Bildiriler kitabl, 51-58, 2001.

[5]. Taşçı E., D. Coşkun N., Pekkan K., Uz V., "Doğal zeolitlerin seramik pigment olarak kullanılabilirliği”, Afyon Kocatepe Üniversitesi Fen ve Mühendislik Bilimleri dergisi, 14, 213-218, 2014.

[6]. Yeşilay S., "Mermer atı̆̆ ilavesi ile mat sır bileşimlerinin üretimi”, Eskişehir Osmangazi Üniversitesi Mühendislik ve Mimarlık Fakültesi dergisi, 26(3), 123-131, 2018.

[7]. Kaya G., Çakı M., “Albit flotasyon atıklarının stoneware ve porselen bünyelerin özelliklerine ve mikroyapılarına etkileri”, Seramik Federasyonu dergisi, 4, 79-85, 2004.

[8]. $\quad$ Bayer Ozturk Z., Eriş M., "Usaqe of wastes of Nevsehir stone cladding in floor file compositions”, Imstec 2016 Bildiriler kitabl, 391-394, 20016.

[9]. Pelino M., "Recycling of Zinc hyrometallurgy wastes in glass and glass ceramic materials, 'Waste Management", 20, 561-568, 2000.

[10]. Park, Heo J. YJ., "Nucleation and cyrstallization kinetics of glass derived from in cinerator flyash waste", Ceramics International, 28, 669-673, 2002

[11]. Erol M., Genç A., Övecoğlu M.L., Yücelen E., Küçükbayrak S., Taptık Y., "Characterization of a glass ceramic produced from thermal power plan fly ashes”, Journal of the Europeon Ceramic Society, 20, 2209-2214, 2002.

[12]. Arslan L., Sağlar B., Toprakçı O., Aycan Ş., Bağren M.N., Bayer Ozturk Z., "Beton karışımlarında uçucu küllerin ve çinko cevheri atı̆̆ının kullanımı”, Imstec 2017 Bildiriler kitabı, 603, 2017.

[13]. Kılınç Mirdalı N., İşler F., "Kromit atığının duvar karosu sırlarında renklendirici olarak değerlendirilmesi”, $C$. $\ddot{U}$. Fen Bilimleri Enstitüsü, 17-1, 11-21, 2008.

[14]. Da Silva R.C., Pionaro S.A., Tebcherani S.M., "Preparation and characterization of glazes from combinations of different industrial wastes”, Ceramics International, 38, (4), 2725-2731, 2012. 